\title{
12. A CASE BASE REASONING SYSTEM ON THE INTERNET FOR KNOWLEDGE SHARING / REUSING ON INFORMATION TECHNOLOGY EDUCATION
}

\author{
Toshio Okamoto \& Masaki Nakagawa \\ Graduated School of Information Systems, \\ University of Electro-Communications \\ 1-5-1 Chofugaoka, Chofu, Tokyo, 182-8585, \\ Japan, \\ okamoto@ai.is.uec.ac.jp
}

\begin{abstract}
We are building a database (DB) which covers actual cases of Information Technology Education (ITE), together with a management system based on Cased Based Reasoning (CBR), accessible to the public through the Internet. Teachers can input their experience of ITE into the system, or check among past cases, similar to their present application. By using this system, teachers from any educational environment can share a common knowledge of ITE practice.
\end{abstract}

\section{Keywords}

Teacher Education, Information Technology, Internet 


\section{Foreword}

Education in information and networking society has brought about a new type of teaching which has not enough history to refer to and apply yet. Existing cases are unknown to the public, and there seems to be no market to exchange ideas and information on such experiments, hidden as teachers' private experiences. It is required to create a place where private knowledge may be shared by a wider group of teachers through ITE for a global refining and quality improvement. Our aim with this research is to construct a Case-Based System for Information Technology taught at high schools nationwide and put it on the Internet. A great number of teachers could access it at and use this system anytime and in anyplace.

The core of the awareness/literacy is expressed by the following four pillars each aiming at the increase of actual advancement of application of ability for operating/utilizing information by computers.

(1) Judgement, Decision, Organizing and Processing of information, Creation of new Information and Raising of ability for transmitting the information.

(2) Understanding of features and structure of information society, its influence on people.

(3) Recognition of the importance of information, Responsibility for information.

(4) Rudiments of information science, Understanding of characteristics of information tools, Mastering basic techniques to handle information.

Primary, secondary and high schools have been allocated their own curriculum to achieve, according to their level of students, in terms of these rationales and goals. It is called "Cross Curriculum." However, it is noteworthy that such subject items of Informatics are taken as a "the rest of our job" and that computer study is hard to handle in math or science class and what is worse, is that "Informatics based thinking/viewpoints" and "system science based thinking/viewpoints" are not

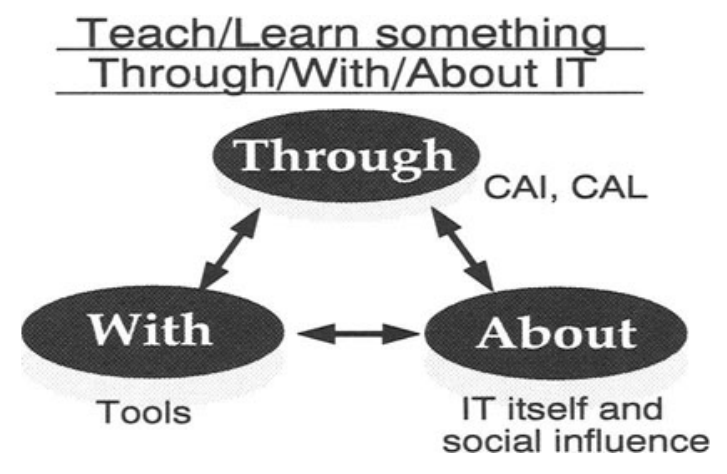

Figure 1 The integrated framework of IT-education 
applied in school subjects in the course of study at school (Okamoto 1997). Of course, there are several tasks about how we treat it as either independent subject curriculum or cross curriculum. Figure 1 shows this feature. Here, "abouteducation" stands for teaching/learning something about information technology/science itself. "With-education" stands for utilisation of information tech-nology as tools for problem solving, communication and so on.

"Through-education" stands for teaching/learning system like CAI and CAL.

\section{Study Purpose}

The users of our system will be teachers who are actually contributing to ITE and others. The system enables us to build a DB for actual practices of ITE and accepts searching and registration of cases. For ITE contributors reference to past similar cases will help to improve their teaching methods. For the rest the system will offer past good and bad examples, as guiding points for their future research.

By the way, what is motivation of this study? In Japan, Ministry of Education is going to introduce the new curriculum about ITE. Especially, in high school level, we decided officially to introduce the new subject related to IT as

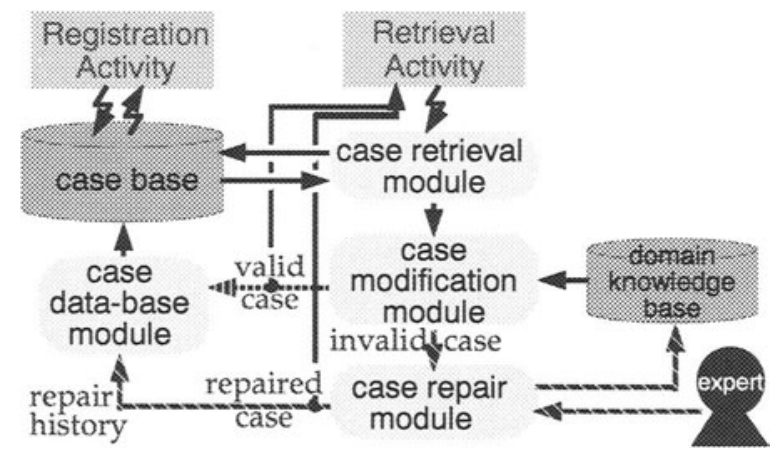

Figure 2 A typical example of CBR

independent/separate one. This subject will become compulsory. So far we have much experience about ITE in existing subjects such as math, science and music/art etc. as tools from primary school level to high school level. Pupils have learned something much for problem solving, communicating as self-expression and so on by using computers, Internet, multimedia and so on.

However, we have not accumulated teachers' teaching experience of it systematically so far. So we try to develop the case based reasoning system about teaching experience of ITE, we can share the knowledge about teaching practices, then can re-use those knowledge by putting this system in Internet environment. 


\section{Case-Based Reasoning}

To construct the above system we use CBR theory of knowledge processing and technology. CBR consists of a set of problem solving architectures leading to a solution, while using past cases of success and failure, similar to a given problem (see Figure 2) (Matsubara 1992). An exhaustive search through the case base takes a lot of time, so CBR reduces the tracking space by applying filtering criteria directly to an index file, so our system can be implemented on middle range computers. When the result matches the problem, it becomes the solution. Still the result can be far-fetched, thus the need of adjustment using appropriate domain knowledge within the case repair module. If this solves the problem, it is added to the DB as a successful case (Kobayashi 1992) (Hammond 1990).

\section{Representation of Cases and Retrieval}

The Case Based System is developed using an interactive WWW interface so that teachers and common users far from each other have access to the same system. It doesn't require specific browsers, and offers search and registration service at anytime and in anyplace. Users' information is processed systematically by the CGI. Cases are kept as HTML files. For efficiency, an index file keeps profile descriptors of the cases and is used in actual searching.

\subsection{Case Base (CB)}

The CB has two kinds of files: CB frames describing class cases, and an index file, with specific descriptors of the cases. Three descriptors create each HTML file frame: the profile, contents and address descriptor.

Profile descriptors : Those descriptors contain the characteristic elements of actual class cases. The combination of class and thematic type leads to a variety of output data and determines the choice of the teaching procedure. In a class computers can be used in a variety of ways. Also, the number of available computers varies from school to school. So the evaluation of the results of using computers in a class is not simple. Table 1 shows the slots of profile descriptors and their possible values (range facets). When actual cases are searched, these values are referred to, and the DB contents are compared to the search tags.

Resultant achievement descriptors : Those descriptors stand for the details about the teaching method/evaluated result of each case. Table 2 shows the examples of slot and value of the resultant achievement for a case. At the end of each class session, achievement of classroom teaching is evaluated by a teacher under his reflective feeling. The points of evaluation for learning behavior are as follows: a) planing/design aspect, b) production/execution aspect, c) evaluation aspect, d) reporting/presentation aspect and so on. The points of evaluation for learners' 
Table 1 Profile descriotors : Range and Facet-values

\begin{tabular}{|c|c|}
\hline Slot Names: & Range of Facet-Values: \\
\hline 1) Teaching subject & Math, Science, Social study, Language, Music, Art etc \\
\hline $\begin{array}{l}\text { 2) Learning content } \\
\text { (topic/goal) }\end{array}$ & $\begin{array}{l}\text { Simulation, Algorithm, Modeling, Communication } \\
\text { skill, Network society etc }\end{array}$ \\
\hline $\begin{array}{l}\text { 3) Relationship between this } \\
\text { topic and IT education }\end{array}$ & $\begin{array}{l}\text { Relativity value between teaching contents and IT } \\
(0-10)\end{array}$ \\
\hline $\begin{array}{l}\text { 4) Teaching time of spending } \\
\text { this topic }\end{array}$ & $X$ hours within the total $Y$ hours \\
\hline 5) Compulsory / Selective & $\mathrm{C}$ or $\mathrm{S}$ \\
\hline 6) Grade & High school $X$ grade \\
\hline 7) Class size & $5-50$ Pupils \\
\hline 8) No. of engaging teachers & $1-3$ \\
\hline 9) Teaching style & Teacher centered - Learner centered \\
\hline 10) Learning form & $\begin{array}{l}\text { Lecturing, Individual learning, Group learning, } \\
\text { Exercise/Practice, Experiment/Lab. work, Discovery } \\
\text { learning, Guided discovery, Exploring learning, } \\
\text { Productive learning, Collaborative learning etc }\end{array}$ \\
\hline $\begin{array}{l}\text { 11) Relative time of computer } \\
\text { usage a class-teaching }\end{array}$ & $X \%$ \\
\hline $\begin{array}{l}\text { 12) The kind of IT-media } \\
\text { (hardware) used in a class }\end{array}$ & $\begin{array}{l}\text { PC, VTR, Projector, Internet, Scanner, Multimedia } \\
\text { device, CAM etc }\end{array}$ \\
\hline $\begin{array}{l}\text { 13) The kind of software used } \\
\text { in a class }\end{array}$ & $\begin{array}{l}\text { Word-processor, Spreadsheet, Database, Drawing } \\
\text { tool, Web-tools, CAD, CASE, Simulator etc }\end{array}$ \\
\hline 14) No. of using computers & $0-50$ terminals \\
\hline
\end{tabular}

achievement are as follows: a) cognitive aspect, b) motional aspect, c) psychomotor aspect, d) interest/motivation aspect, e) attitude aspect and so on. Additionally, following slots are provided: list of products by learners, the degree of self-evaluation of teaching, improved points in the teaching, the degree of preparation loading of teaching. Those slots/values become a kind of solution of which users(teachers) ask this system.

Address descriptors : Those mean the environmental information of each teaching class: school name, where the teaching has been carried out, teacher's name(s), class name(s), class tag and students' grade, eventually school URL. 


\begin{tabular}{|c|c|}
\hline Slot Names: & Range of Facet-Values: \\
\hline 1) Teaching strategy & Fill in freely \\
\hline 2) Teaching tactics & Fill in freely \\
\hline 3) Used materials & Fill in freely \\
\hline $\begin{array}{l}\text { 4) Evaluation stance for learning } \\
\text { behavior }\end{array}$ & $\begin{array}{l}\text { Investigation/Analysis aspect: } \\
\text { Planing/Design aspect: } \\
\text { Production/Execution aspect: } \\
\text { Evaluation aspect: } \\
\text { Reporting/Presentation aspect: } \\
\text { The others aspect: } \\
\text { Fill in freely for each sub-slot }\end{array}$ \\
\hline 5) Evaluation method / tools & Fill in freely \\
\hline 6) Achievement of learners & $\begin{array}{l}\text { Cognitive aspect: } \\
\text { Emotional aspect: } \\
\text { Psycho-motor aspect: } \\
\text { Interest/Motivation aspect: } \\
\text { Attitude aspect: } \\
\text { Fill in freely for each sub-slot }\end{array}$ \\
\hline 7) Products by learners & Enumerate pupils' products concretely \\
\hline 8) Self-evaluation of teaching & $0-100$ with comments \\
\hline 9) Improved points & Fill in freely \\
\hline 10) Preparation loading of teaching & $0-100$ with comments \\
\hline
\end{tabular}

Table 2 Resultant achievement descriptors : Range and Facet-values

\subsection{Case Search}

The case search module draws search patterns from the information clients have given (keywords from the key descriptor's value column and search formats). Search formats, class genre and class contents determine the values of the appropriate slot. The system searches for cases matching them in the index file, inputs these cases into a similarity function and draws as satisfactory cases as possible.

Then a user can take a more adequate case by similarity function from the case base. Some slots in profile descriptors have numerical values. Of course, a user would input the numerical value which he requires for some slots. So the system tries to compute the $\mathrm{N}$-dimensional vector space distance of the corresponding slotsvalues between a user's asking case and every case in the case base, then the system chooses the case with the most neighboring distance computed by this similarity function.

\section{Learning}

The main system's training consists in the roles and functions of the case modification, the case diagnosis and the case repair modules. 


\subsection{Case Modification}

In case searching, the most similar case, according to the user's search conditions, is gathered. The profile descriptor of the searched case and the user input search conditions are rarely in perfect concordance, so cases are tuned by the modification mechanism. During tuning, the system gives some alternative values so the user can modify the case easily (Figure 3). Our system is used as a tool for teachers so the system allows the teacher to decide the value of the modified slot.

\subsection{Case Diagnosis}

The case diagnosis mechanism (Figure 4) is testing the validity of the case which was modified and using the domain knowledge base of relations between the slots or the slots' value. If the result is valid, the case and the modification information (modified slots and values) are passed to the case repair module. If not, the reason of invalidity is shown to the user, and a new modify process starts. If the system has knowledge of suitable values for the slots, it shows some alternative values. By using domain knowledge, our system evades failures which generally happen in the case repair process. Users modify the searched case by changing slot values. Based on these changes the system calls the predicates and the slots which need diagnosis are determined and checked. The system creates diagnosis conditions based on the domain knowledge for each slot. If all conditions are fulfilled, the modified case is evaluated as valid, else, the system uses the CB to check these conditions and shows two information to the user: the reason why the case is invalid and alternative values for the slots which were evaluated as false.

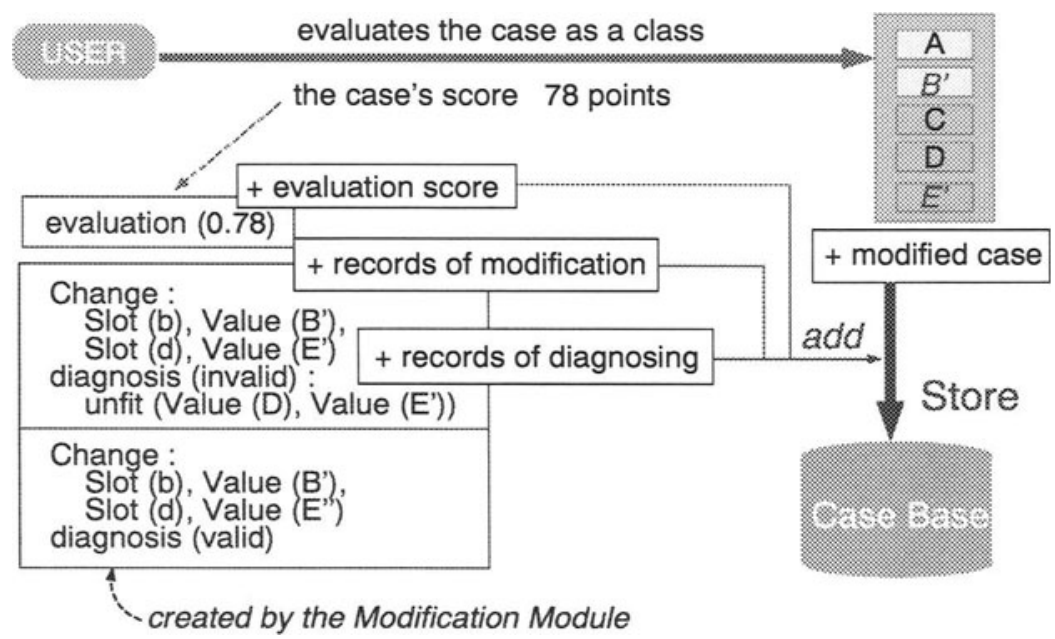

Figure 3 An example of modification 


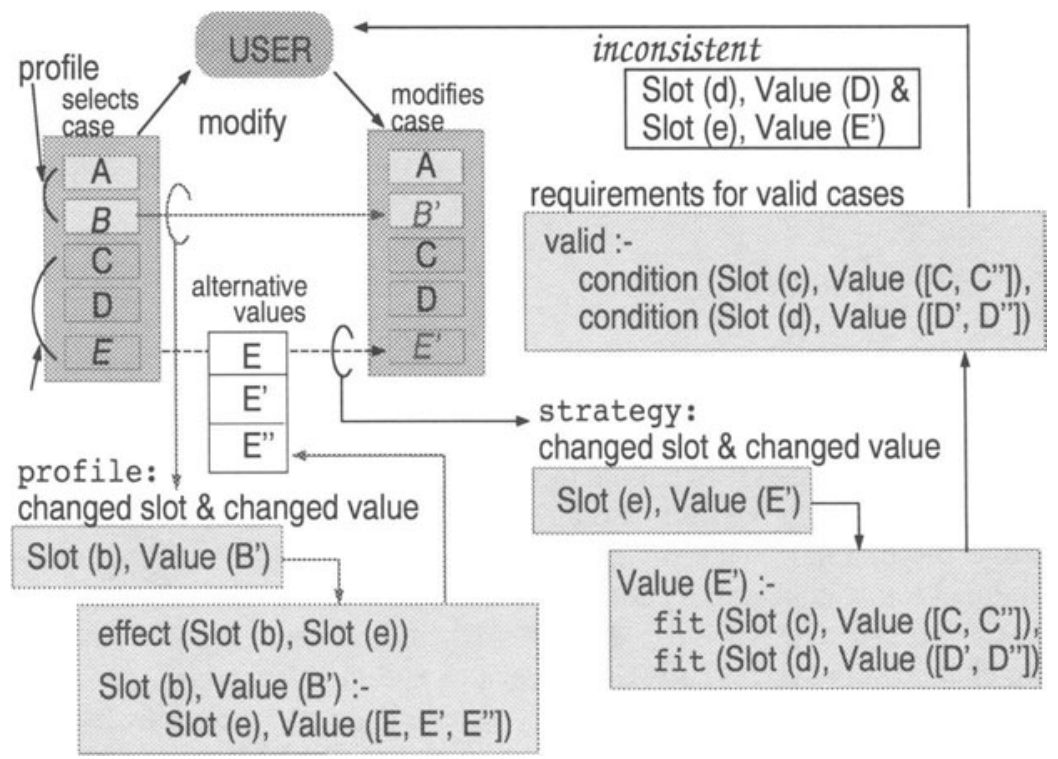

Figure 4 An example of diagnose

\subsection{Case Repairing}

The repairing module means to store the modified case into the case base and the system can look for a more adequate case efficiently, adding/utilizing the revised information related to diagnosed result. So the system grows incrementally with the function of so-called "knowledge acquisition." The acquired knowledge is stored in the rule base of the expert system as a simulator, therefore works more effectively in retrieving/diagnosing process of modifying a case by a user in later session. After the case diagnosis, the diagnosed case is attached features with the case repair mechanism and is stored in the CB. The system adds repairing information to a case repair information frame, as follows:

- records of evaluation : Two types of information: the evaluation score (an integer from 0 to 100) and the reason for the evaluation (free text).

- records of modification : Modified slots and modified values.

- records of diagnosing : Three types of information: the result of diagnosing (proper/improper), a pointer to the searched case and the reason why the modified case is invalid (only for invalid cases).

These information are used for case search, case modification and case diagnose (Fig.3, Fig.4). Suitable cases are searched in consideration of the records of evaluation (evaluation score). The user can refer to evaluation comments given by 
other users. If the searched case has been referred before and has an evaluation score, the system records the average of the scores to a slot which expresses the quality of the case. The system supports the user's case modification process with the records of modification and the records of diagnosing. The records of diagnosing are used to diagnose a modified case efficiently. During case search, the system looks for the case input by the user (we call this case the original case). If nothing matching is found, the system searches the modified CB, based on the original case and the case modification information frame.

\section{Evaluation and Discussion}

As the system requires from users to specify the desired relative value between the input case and the actual teaching subjects stored in the DB, a precise assessment is achieved. Also, as desired patterns have to appear in the teaching contents, a more flexible search than simple keyword matching is allowed.

The system has now been actually implemented, can accept case registration and provides the search function. We had some experiments at three different remote sites (Tokyo, Tottori and Naruto) to examine its reliability. At present, we have 157 cases in the system and tested around 70 searching trials. The ratio of appropriate hitting was 71 including case modification. However, we can conclude that this kind of ratio is dependent on the content quality (validity) and grain size of case explaining by a case registrar (teacher).

\section{References}

Okamoto T et al. (1997) The Practice and Current Situation of IT-Education in Primary /Secondary School Education, J. of IPSJ, 38, 7, 594-9.

Kobayashi S. (1992) Present and Future of CBR, J. of JSAI, 7, 4, 559-65.

Matsubara H. (1992) CBR as a Mechanism for Reason and Learning, J. of JSAI, 7,4,567-75.

Hammond K.J. (1990) Case-based Planning : a framework for planning from experience, Cognitive Science, 14, 385-443.

\section{Biography}

He took his Dr. of Engineering from Tokyo Institute of Technology. Presently, He is a Professor in the Graduate School of Information Systems, University of ElectroCommunications, engaging in AI, ITE, CAI research. He is a vice president of the Japanese Society of Information and System in Education and a member of the Board of the Japanese Society of Educational Technology, a.s.o. and has a lot of important official functions for promoting the field of computers and education in Japan. 